\title{
Agricultural optimization with limited resources using duality
}

\author{
Angel Ramon Sanchez Delgado ${ }^{1,2}$ (D), Sergio Drumond Ventura ${ }^{2}$ (D) \& Pedro \\ Marcio Ferreira ${ }^{2}$
}

(1) Universidade Federal Rural do Rio de Janeiro, Instituto de Ciências Exatas, Departamento de Matemática, Programa de Mestrado em Modelagem Matemática e Computacional, Rodovia BR 465, Km 07, Zona Rural, Seropédica 23897-000, Rio de Janeiro, Brazil. E-mail: asanchez@ufrrj.br

(2) Universidade Federal Rural do Rio de Janeiro, Instituto de Ciências Exatas, Departamento de Matemática, Rodovia BR 465, Km 07, Zona Rural, Seropédica 23897-000, Rio de Janeiro, Brazil. E-mail: ventura@ufrrj.br, pedroborgesengen@gmail.com

Delgado A.R.S., Ventura S.D. \& Ferreira P.M. (2020) Agricultural optimization with limited resources using duality. Pesquisa e Ensino em Ciências Exatas e da Natureza, 4: e1477.

http://dx.doi.org/10.29215/pecen.v4i0.1477

Academic editor: Eudes Leite de Lima. Received: 14 December 2019. Accepted: 06 August 2020. Published: 08 August 2020.

Otimização agrícola com recursos limitados usando dualidade

Resumo: Água e nitrogênio são insumos fundamentais para o desenvolvimento de qualquer cultura agrícola, e quando estão correlacionados com a produção obtida, há uma função analítica que representa aproximadamente a produção em relação à água e ao nitrogênio. Considerando que no ambiente do agronegócio e de tomada de decisão, é importante conhecer quantitativamente a produção máxima e a receita líquida máxima que uma determinada safra gera no caso em que esses insumos são limitados, neste trabalho, apresentamos um procedimento computacional usando a teoria da dualidade e o método da barreira logarítmica para resolver ambos os problemas. Para avaliar a metodologia apresentada, realizamos alguns testes numéricos com base em dados conhecidos para as culturas do melão, da alface americana, pêra laranja e aveia. Com base nos resultados obtidos, podemos concluir que a metodologia apresentada constitui uma alternativa confiável, considerando os resultados conhecidos na literatura para tais culturas.

Palavras chave: Água, nitrogênio, dualidade, barreira logarítmica, programação quadrática.

Abstract: Water and nitrogen are fundamental inputs for the development of any agricultural crop, and when they are correlated with the production obtained, there is an analytical function that roughly represents the production in relation to water and nitrogen. Considering that in the agribusiness and decision-making environment, it is important to know quantitatively the maximum production and maximum net revenue that a given crop generates in the case where these inputs are limited, in this work we present a computational procedure using duality theory and logarithmic barrier method to solve both problems. To evaluate the presented methodology, we performed some numerical tests based on data known for the cultures, melon, american lettuce, orange-pear and oats. Based on the results obtained, we may conclude that the presented methodology constitutes a reliable alternative, considering the results known in the literature for such cultures.

Key words: Water, nitrogen, duality, logarithmic barrier, quadratic programming.

\section{Introduction}

It is well-known that several factors related to soil, plant and atmosphere interact with each other, determining the productivity of agricultural crops. Certainly, there is a functional relationship between these factors and crop production, characteristics of each environmental 
condition. Crop response may vary across different soil types, climates and also as a result of the amount and frequency of water application, nitrogen and other inputs (Frizzone et al. 2005).

Agricultural production function or response is defined as that which expresses the physical relationship between the quantities used of a certain set of inputs and the maximum physical quantities that can be obtained from the product for a given used technology. In general, the problem is finding an optimal input-output solution that maximizes production and net revenue separately, subject to pre-fixed resource (or input) constraints and a given cost and pricing structure.

If production functions were known precisely, it would be possible to accurately select the optimal level of water and nitrogen for a particular situation; but such functions are restricted to large variations in soil-climate, making it difficult to predict crop yields accurately. In practice linear regressions are generated to represent "good approximations" of these functions. The quality of the adjustment, which indicates the proportion of variation of the function, is indicated by a descriptive unit known as the coefficient of determination $\left(r^{2}\right)$.

Proper water management is critical in irrigated agriculture, considering that the agricultural sector is the largest consumer of water and that water resources are essential and strategic. According to Figueiredo et al. (2008), a fundamental change should occur in irrigation practices in the coming years, due to economic pressures on farmers, growing competition for resource use and the environmental impacts of irrigation. They think that such factors should motivate a change in the irrigation paradigm, focusing on economic efficiency rather than crop water demand. Regarding the nitrogen resource, considering that at present the costs are increasingly variable and that the demand in Brazil is growing every day, it is necessary to respect the environmental issues related to the preservation of the soil, as a fundamental piece for a sustainable agriculture.

In this work we present a dual view of agricultural optimization with limited inputs (water depth and nitrogen dose), associated with the maximization of production and the maximization of the net agricultural income of a given crop respectively. We present a computational procedure using duality theory and logarithmic barrier method (Bertsekas 2004) to solve both problems, and in order to evaluate the methodological performance, we carried out numerical experiments with melon crops (Rocha Junior et al. 2016), american lettuce (Marques Silva et al. 2008), pear-orange (Bertonha et al. 1999) and oats (Frizzone et al. 1995). The reason for choosing these agricultural crops is due to the good coefficients of determination $\left(r^{2}\right)$ that presented the analytical functions of production or responses of each culture in the considered scenario.

\section{Material and Methods}

Let $y(w, n)$ be the response (or production) function of a given crop $\left(\mathrm{kg} \cdot \mathrm{ha^{-1 }}\right)$ in relation to the water depth $w(\mathrm{~mm})$ and the nitrogen dose $(\mathrm{kg})$, generally a nonlinear function, and $w_{l}, w_{u}, n_{l}, n_{u}(\mathrm{~mm})$ lower and upper bounds of $w$ and $n$ respectively, being $w_{l}, w_{u}, n_{l}, n_{u} \geq 0$, $w_{u} \geq w_{l}$ and $n_{u} \geq n_{l}$. In this context, the first problem to consider is primal:

$$
\begin{aligned}
\text { Maximize } & y(w, n) \\
\text { Subject to: } & w_{l} \leq w \leq w_{u} \\
& n_{l} \leq n \leq n_{u} .
\end{aligned}
$$

The problem in (1) represents a nonlinear programming problem in the twodimensional box $\left[w_{l}, w_{u}\right] \times\left[n_{l}, n_{u}\right]$ (Bazaraa et al. 1993). Another interesting problem to study in agricultural optimization with water and fertilizer limitations is the maximization of the net income obtained from the planting of a certain crop. Considering that the benefit is proportional to the productivity, then: 


\section{Agricultural optimization using duality}

$$
\begin{array}{cl}
\text { Maximize } & R L(w, n)=p_{c} y(w, n)-c_{w} w-c_{n} n \\
\text { Subject to: } & w_{l} \leq w \leq w_{u} \\
& n_{l} \leq n \leq n_{u}
\end{array}
$$

where $p_{c}$ represents the price of the crop $\left(R \$ \cdot h a^{-1}\right), c_{w}$ the cost of the water depth $\left(R \$ \cdot m m^{-1}\right.$. $\left.h a^{-1}\right), c_{n}$ the nitrogen dose cost $\left(R \$ \cdot \mathrm{kg}^{-1} \cdot h \mathrm{a}^{-1}\right)$ and $R L(w, n)$ the net revenue obtained from planting $\left(R \$ \cdot h a^{-1}\right)$. In the following, suppose that $y(w, n)=a w^{2}+b n^{2}+c w n+d w+e n+f$, where $a, b, c, d, e, f \in \mathbb{R}$ and $a, b, c<0$. So, (1) is equivalent to the problem:

$$
\begin{array}{ll}
\text { Minimize } & -y(w, n)=\frac{1}{2}(w, n) Q\left(\begin{array}{l}
w \\
n
\end{array}\right)-(d, e)\left(\begin{array}{l}
w \\
n
\end{array}\right)-f \\
\text { Subject to: } & A\left(\begin{array}{l}
w \\
n
\end{array}\right) \leq \rho
\end{array}
$$

where $Q=\left(\begin{array}{cc}-2 a & -c \\ -c & -2 b\end{array}\right), A=\left(\begin{array}{cc}1 & 0 \\ -1 & 0 \\ 0 & 1 \\ 0 & -1\end{array}\right), \rho=\left(\begin{array}{c}w_{u} \\ -w_{l} \\ n_{u} \\ -n_{l}\end{array}\right)$. Note that $Q$ is a symmetric positive definite matrix $(a, b, c<0)$, so that the objective function $-y(w, n)$ is strictly convex. In this case the dual problem associated with problem $(\mathrm{P})$ is given by:

$$
\begin{array}{cl}
\text { Maximize } & \theta(u) \\
\text { Subject to: } & u \in \mathbb{R}_{+}^{4},
\end{array}
$$

where:

$$
\theta(u)=\inf \left\{\frac{1}{2}(w, n) Q\left(\begin{array}{c}
w \\
n
\end{array}\right)-(d, e)\left(\begin{array}{c}
w \\
n
\end{array}\right)-f+u^{T}\left(A\left(\begin{array}{c}
w \\
n
\end{array}\right)-\rho\right):\left(\begin{array}{l}
w \\
n
\end{array}\right) \in R^{2}\right\}
$$

For a given $u$, the function: $\frac{1}{2}(w, n) Q\left(\begin{array}{l}w \\ n\end{array}\right)-(d, e)\left(\begin{array}{l}w \\ n\end{array}\right)-f+u^{T}\left(A\left(\begin{array}{l}w \\ n\end{array}\right)-\rho\right)$ is convex and therefore a necessary and sufficient condition for one $\left(\begin{array}{c}w \\ n\end{array}\right)$ to be minimal is that its gradient be zero, i.e.:

$$
Q\left(\begin{array}{l}
W \\
n
\end{array}\right)+A^{T} u-\left(\begin{array}{l}
d \\
e
\end{array}\right)=0
$$

Therefore, the dual problem associated with $(\mathrm{P})$ is given by:

$$
\begin{aligned}
& \text { Maximize } \frac{1}{2}(w, n) Q\left(\begin{array}{l}
w \\
n
\end{array}\right)-(d, e)\left(\begin{array}{l}
w \\
n
\end{array}\right)-f+u^{T}\left(A\left(\begin{array}{l}
w \\
n
\end{array}\right)-\rho\right) \\
& \text { Subject to: } Q\left(\begin{array}{l}
w \\
n
\end{array}\right)+A^{T} u=\left(\begin{array}{l}
d \\
e
\end{array}\right) \\
& u \in \mathbb{R}_{+}^{4} \text {. }
\end{aligned}
$$

From (4) we have $-(w, n) Q\left(\begin{array}{l}w \\ n\end{array}\right)=u^{T} A\left(\begin{array}{l}w \\ n\end{array}\right)-(d, e)\left(\begin{array}{l}w \\ n\end{array}\right)$, so that the objective function of $(\mathrm{D})$ is $\frac{1}{2}(w, n) Q\left(\begin{array}{c}w \\ n\end{array}\right)-(d, e)\left(\begin{array}{l}w \\ n\end{array}\right)-f+u^{T}\left(A\left(\begin{array}{c}w \\ n\end{array}\right)-\rho\right)=-\frac{1}{2}(w, n) Q\left(\begin{array}{l}W \\ n\end{array}\right)-\rho^{T} u-f$.

Thus, problem (D) can be written as: 


$$
\begin{array}{cl}
\text { Maximize } & -\frac{1}{2}(w, n) Q\left(\begin{array}{l}
w \\
n
\end{array}\right)-\rho^{T} u-f \\
& Q\left(\begin{array}{l}
w \\
n
\end{array}\right)+A^{T} u=\left(\begin{array}{l}
d \\
e
\end{array}\right)
\end{array}
$$

Subject to:

$$
u \in \mathbb{R}_{+}^{4} \text {. }
$$

Note that from (4), as $Q^{-1}$ exists, then $\left(\begin{array}{l}w \\ n\end{array}\right)=Q^{-1}\left(\left(\begin{array}{l}d \\ e\end{array}\right)-A^{T} u\right)$ or $(w, n)=((d, e)-$ $\left.u^{T} A\right) Q^{-1}$ and thus:

$$
\begin{aligned}
-\frac{1}{2}(w, n) & Q\left(\begin{array}{l}
w \\
n
\end{array}\right)-\rho^{T} u-f=-\frac{1}{2}(w, n) Q Q^{-1}\left(\left(\begin{array}{l}
d \\
e
\end{array}\right)-A^{T} u\right)-\rho^{T} u-f \\
= & -\frac{1}{2}(w, n)\left(\left(\begin{array}{l}
d \\
e
\end{array}\right)-A^{T} u\right)-\rho^{T} u-f \\
= & -\frac{1}{2}(w, n)\left(\begin{array}{l}
d \\
e
\end{array}\right)+\frac{1}{2}(w, n) A^{T} u-\rho^{T} u-f \\
= & -\frac{1}{2}\left((d, e)-u^{T} A\right) Q^{-1}\left(\begin{array}{l}
d \\
e
\end{array}\right)+\frac{1}{2}\left((d, e)-u^{T} A\right) Q^{-1} A^{T} u-\rho^{T} u-f \\
= & -\frac{1}{2}(d, e) Q^{-1}\left(\begin{array}{l}
d \\
e
\end{array}\right)+\frac{1}{2} u^{T} A Q^{-1}\left(\begin{array}{l}
d \\
e
\end{array}\right)+\frac{1}{2}(d, e) Q^{-1} A^{T} u-\frac{1}{2} u^{T} A Q^{-1} A^{T} u-\rho^{T} u-f \\
= & -\frac{1}{2}(d, e) Q^{-1}\left(\begin{array}{l}
d \\
e
\end{array}\right)+(d, e) Q^{-1} A^{T} u-\frac{1}{2} u^{T} A Q^{-1} A^{T} u-\rho^{T} u-f \\
= & -\frac{1}{2}(d, e) Q^{-1}\left(\begin{array}{l}
d \\
e
\end{array}\right)-\frac{1}{2} u^{T} H u+\sigma^{T} u-f,
\end{aligned}
$$

where $\sigma=A Q^{-1}\left(\begin{array}{l}d \\ e\end{array}\right)-\rho$ and $H=A Q^{-1} A^{T} . H$ is symmetric and positive definite.

So, problem (D) can be written as:

(D) Maximize $-\frac{1}{2}(d, e) Q^{-1}\left(\begin{array}{l}d \\ e\end{array}\right)-\frac{1}{2} u^{T} H u+\sigma^{T} u-f$

Subject to: $u \in \mathbb{R}_{+}^{4}$.

By doing $g=\frac{1}{2}(d, e) Q^{-1}\left(\begin{array}{l}d \\ e\end{array}\right)$, the previous problem can be written as:

(D) Maximize $-\frac{1}{2} u^{T} H u+\sigma^{T} u-(g+f)$

Subject to: $u \in \mathbb{R}_{+}^{4}$,

or, equivalently:

(D)

$$
\begin{aligned}
\text { Minimize } & \frac{1}{2} u^{T} H u-\sigma^{T} u+(g+f) \\
\text { Subject to: } & u \in \mathbb{R}_{+}^{4} .
\end{aligned}
$$

Following the logarithmic barrier methodology, for a given $\mu>0$, we associate to the objective function of (D), the logarithmic barrier function:

$$
\varphi_{\mu}(u)=\frac{1}{2} u^{T} H u-\sigma^{T} u+(g+f)+\mu \sum_{j=1}^{4} \operatorname{Ln}\left(u_{j}\right),
$$




\section{Agricultural optimization using duality}

and we search to

$$
\text { Minimize } \varphi_{\mu}(u)
$$

Moreover, $u$ solves this unconstrained problem for each $\mu>0$, if and only if $\nabla \varphi_{\mu}(u)=0$. Thus, we seek $(u, z)>0$ such that:

where $z=\left(\begin{array}{l}\frac{\mu}{u_{1}} \\ \frac{\mu}{u_{2}} \\ \frac{\mu}{u_{3}} \\ \frac{\mu}{u_{4}}\end{array}\right)=\mu u^{-1}$. Note that as $z_{j}=\mu u_{j}^{-1}$ so $z_{j} u_{j}=\mu$, and now we seek to solve the system of nonlinear equations:

$$
\begin{gathered}
H u+z=\sigma \\
z_{j} u_{j}=\mu \quad(j=1,2,3,4) .
\end{gathered}
$$

Applying Newton's method to solve the nonlinear system (5)-(6), one looks for a direction $\Delta u=\left(\Delta u_{1}, \Delta u_{2}, \Delta u_{3}, \Delta u_{4}\right) \in \mathbb{R}^{4}$ and $\Delta z=\left(\Delta z_{1}, \Delta z_{2}, \Delta z_{3}, \Delta z_{4}\right) \in \mathbb{R}^{4}$ such that:

$$
\begin{gathered}
H(u+\Delta u)+(z+\Delta z)=\sigma, \\
\left(z_{j}+\Delta z_{j}\right)\left(u_{j}+\Delta u_{j}\right)=\mu(j=1,2,3,4) .
\end{gathered}
$$

Hence:

$$
\begin{gathered}
H \Delta u+\Delta z=\sigma-H u-z=\theta \\
z_{j} \Delta u_{j}+u_{j} \Delta z_{j}=\mu-z_{j} u_{j}=\tau_{\mu}(j=1,2,3,4) .
\end{gathered}
$$

Following is the computational procedure to solve (1).

\section{Procedure}

Data: $a, b, c, d, e, f \in \mathbb{R}$ e $a, b, c<0, w_{l}, w_{u}, n_{l}, n_{u} \geq 0 ; w_{u} \geq w_{l}$ e $n_{u} \geq n_{l}$, $\varepsilon, \xi \in(0,1), \mu_{0}>0, u \in \mathbb{R}_{++}^{4}$.

Set

$$
\begin{aligned}
& Q=\left(\begin{array}{cc}
-2 a & -c \\
-c & -2 b
\end{array}\right), A=\left(\begin{array}{cc}
1 & 0 \\
-1 & 0 \\
0 & 1 \\
0 & -1
\end{array}\right), \rho=\left(\begin{array}{c}
w_{u} \\
-w_{l} \\
n_{u} \\
-n_{l}
\end{array}\right), \mu=\mu_{0} \\
& \sigma=A Q^{-1}\left(\begin{array}{l}
d \\
e
\end{array}\right)-\rho, Q^{-1}=\frac{1}{c^{2}-4 a b}\left(\begin{array}{cc}
2 b & -c \\
-c & 2 a
\end{array}\right), H=A Q^{-1} A^{T}, \quad z=\mu u^{-1} \\
& \theta=\sigma-H u-z, \tau_{\mu}=\mu-z_{j} u_{j}
\end{aligned}
$$

While $\quad \operatorname{Max}\left\{\|\theta\|,\left|\tau_{\mu}\right|\right\}>\varepsilon$ 


$$
\Delta u=\left(\Delta u_{1}, \Delta u_{2}, \Delta u_{3}, \Delta u_{4}\right), \Delta z=\left(\Delta z_{1}, \Delta z_{2}, \Delta z_{3}, \Delta z_{4}\right)
$$

Solve

$$
\begin{aligned}
& H \Delta u+\Delta z=\theta \\
& z_{j} \Delta u_{j}+u_{j} \Delta z_{j}=\tau_{\mu}(j=1,2,3,4) \\
& \text { Set } \quad \alpha=\min \left\{\frac{\|u\|}{\|\Delta u\|}, \frac{\|z\|}{\|\Delta z\|}\right\} \\
& u=u+0.999 \alpha \Delta u \\
& z=z+0.999 \alpha \Delta z \\
& \mu=\xi \mu
\end{aligned}
$$

\section{Reevalutate $\theta, \tau_{\mu}$}

Set

$$
\left(\begin{array}{l}
w \\
n
\end{array}\right)=Q^{-1}\left(\left(\begin{array}{l}
d \\
e
\end{array}\right)-A^{T} u\right) .
$$

Note that the above procedure can also be applied to solve problem (2), where we seek to maximize net revenue $R L(w, n)=p_{c} y(w, n)-c_{w} w-c_{n} n$, since: $R L(w, n)=p_{c} y(w, n)-c_{w} w-$ $c_{n} n=p_{c}\left(a w^{2}+b n^{2}+c w n+d w+e n+f\right)-c_{w} w-c_{n} n=\bar{a} w^{2}+\bar{b} n^{2}+\bar{c} w n+\bar{d} w+\bar{e} n+\bar{f}$, where $\bar{a}=p_{c} a, \bar{b}=p_{c} b, \bar{c}=p_{c} c, \bar{d}=p_{c} d-c_{w}, \bar{e}=p_{c} e-c_{n}$, and $\bar{f}=p_{c} f$.

\section{Results and Discussion}

To test the previous procedure, we used the production functions of melon (Rocha Júnior et al. 2016), american lettuce (Marques Silva et al. 2008), orange-Pear (Bertonha et al. 1999) and oats (Frizzone et al. 1995). The formulas of these functions are shown in Table 1.

The test cultures used here (melon, american lettuce, pear orange and oats) were not selected because they presented some difficulty but because the specific analytical formulas for production of each culture were already known in relation to the water depth and nitrogen dose.

To obtain the melon production function, Rocha Júnior et al. (2016) tested ten statistical models that, according to Hexem \& Heady (1978) and Soares et al. (1999), satisfactorily represent a function of culture production. Among these models, the one best fitting the data of the experiment was chosen, considering the adjusted coefficients $r^{2}$ and $r^{2}$ adjusted, the value of the $\mathrm{F}$ test of the analysis of variance, the values of the t test for all coefficients and the signs of the variables of the analyzed models.

In the study of the production function and economic analysis of american lettuce, Marques Silva et al. (2008), follow the procedure adopted by Frizzone (1986). The analytical formula of production shown in Table 1 had a determination coefficient $\left(r^{2}\right)$ of 0.8311 , and thus, $83.11 \%$ of the variation in commercial lettuce productivity is explained by the variation in water and nitrogen dose.

For the pear orange culture, Bertonha et al. (1999) use a second-degree polynomial to evaluate physical production as a function of used levels of water and nitrogen, and through a regression, obtain the analytical formula shown in Table 1, with a coefficient of determination $\left(r^{2}\right)$ of 0.7504

Table 1. Analytical formulas of production of the culture's: melon, american lettuce, orange-pear and oats.

\begin{tabular}{ll}
\hline Cultures & \multicolumn{1}{c}{$\boldsymbol{y}(\boldsymbol{w}, \boldsymbol{n})$} \\
\hline Melon & $y(w, n)=52.40174118 \mathrm{w}+111.1536525 \mathrm{n}-0.038815548 \mathrm{w}^{2}-0.279112997 \mathrm{n}^{2}$ \\
American lettuce & $y(w, n)=-12490+388.1 \mathrm{w}-6.02 \mathrm{n}-1.042 w^{2}-0.04563 n^{2}-0.1564 \mathrm{wn}$ \\
Orange-pear & $y(w, n)=0.306+1.01 \times 10^{-2} n-1.46 \times 10^{-5} n^{2}+4.35 \times 10^{-4} w-4.47 \times 10^{-8} w^{2}$ \\
Oats & $y(w, n)=3.575 \times 10^{-2} w+1.554 \times 10^{-2} n-5.6 \times 10^{-5} w^{2}-5.1 \times 10^{-5} n^{2}$ \\
\hline
\end{tabular}


Finally, in relation to the culture of oats, in Frizzone et al. (1995), the function of oat dry matter production was defined using the quadratic polynomial model together with analyzes of variance of the regression and significance of the coefficients of the variables. The determination coefficient $\left(r^{2}\right)$ was 0.8964 .

Note that the bilinear forms of the production functions considered here are composed by the linear terms of the variables $w$ and $n$, the quadratic terms $w^{2}$ and $n^{2}$, and a cross term between the variables, $w n$. This last term appears only in the analytical formula of production of the american lettuce crop.

The ranges $\left[w_{l}, w_{u}\right]$ and $\left[n_{l}, n_{u}\right]$ considered for melon were [150.750] and [100.300] respectively, [150.300] and [100.250] for american lettuce, [0.6000] and [0.5000] for pear-orange and $[0,0.6]$ and $[0,0.5]$ for oats. Water and nitrogen costs were $\mathrm{R} \$ 0.318$ and $\mathrm{R} \$ 3.5$ for melon, $\mathrm{R} \$$ 0.44 and $R \$ 2.09$ for american lettuce and $R \$ 0.20$ and $R \$ 0.50$ for oats respectively. The prices considered were R\$ 0.58 for melon, $\mathrm{R} \$ 0.80$ for lettuce and $\mathrm{R} \$ 150$ for oats. For the orange-pear crop, only productivity was maximized in response to water and nitrogen application. In Bertonha et al. (1999), the costs and prices associated with pear oranges are not given. Table 2 presents the results obtained by the Procedure, as well as the literature regarding the yield of each crop.

In the case of melon crop, we observe a total compatibility between the results obtained through the Procedure and those obtained in Rocha Junior et al. (2016). For american lettuce culture crop, the optimal yield obtained by the Procedure shows a small difference in values when compared to those presented by Marques Silva et al. (2008), as well as the values obtained from the water depth and nitrogen dose. Regarding the orange pear crop, although optimal productivity is obtained very closely to that in Bertonha et al. (1999), it is required $228.8 \mathrm{~mm}$ more water than in the Procedure. Remember that among the cultures considered is the one with the lowest determination coefficient. Finally, the results obtained in Frizzone et al. (1995) and the Procedure for oat cultivation were numerically almost the same.

It is important to highlight that the production results obtained in Table 2 are satisfactory if we consider for example, that the average production of melon known in the Submédio São Francisco region is $30.000 \mathrm{~kg} \cdot h \mathrm{a}^{-1}$, that of american lettuce in the experimental area of Horticulture located in the Municipality of Cáceres-MT of $24.130 \mathrm{~kg} . \mathrm{ha}^{-1}$, the one of pear orange in the citrus belt of São Paulo and Triângulo / Sudoeste Mineiro of 2.24 boxes. tree ${ }^{-1}$ and the one of oats in the Experimental Farm of the Agronomy Course of the State University of Minas Gerais, Campus de Passos, 7 t. $h a^{-1}$.

Table 2. Water depth $w$, nitrogen dose $n$ and optimal productivity $y(w, n)$.

\begin{tabular}{|c|c|c|c|c|}
\hline Cultures & Methodology & $w(\boldsymbol{m m})$ & $n(k g)$ & $y(w, n)$ (production) \\
\hline \multirow[t]{2}{*}{ Melon } & Procedure & 675.01 & 199.12 & $28.752 .26\left(\mathrm{~kg} \cdot \mathrm{ha} \mathrm{a}^{-1}\right)$ \\
\hline & Rocha Junior et al. (2016) & 675 & 199.1 & $28.752 .3\left(\mathrm{~kg} \cdot h \mathrm{a}^{-1}\right)$ \\
\hline American & Procedure & 211.91 & 287.49 & $26.987\left(\mathrm{~kg} \cdot \mathrm{ha} \mathrm{a}^{-1}\right)$ \\
\hline Lettuce & Marques Silva et al. (2008) & 208.03 & 290.5 & $27.004 .49\left(\mathrm{~kg} \cdot \mathrm{ha} \mathrm{a}^{-1}\right)$ \\
\hline \multirow[t]{2}{*}{ Orange-pear } & Procedure & 4.865 .8 & 351.75 & $3.11106\left(\right.$ boxes $\cdot$ tree $\left.^{-1}\right)$ \\
\hline & Bertonha et al. (1999) & 5.095 .6 & 345.9 & $3.2\left(\right.$ boxes $\cdot$ tree $\left.^{-1}\right)$ \\
\hline \multirow[t]{2}{*}{ Oats } & Procedure & 319.20 & 152.35 & $6.8894\left(t \cdot h a^{-1}\right)$ \\
\hline & Frizzone et al. (1995) & 319.2 & 152.36 & 6.9 t. $\left(t \cdot h a^{-1}\right)$ \\
\hline
\end{tabular}

In Figure 1 we can visualize each iterations of the implemented Procedure regarding the optimal productivity of each considered crop. Note that the Procedure generates a sequence of approximate solutions that converges to the optimal solution of the problem when $\mu \rightarrow 0$. Graphically, this sequence defines a smooth curve called the central path associated with the production of each culture (see Figure 1). 


\section{Agricultural optimization using duality}

\section{Lettuce}

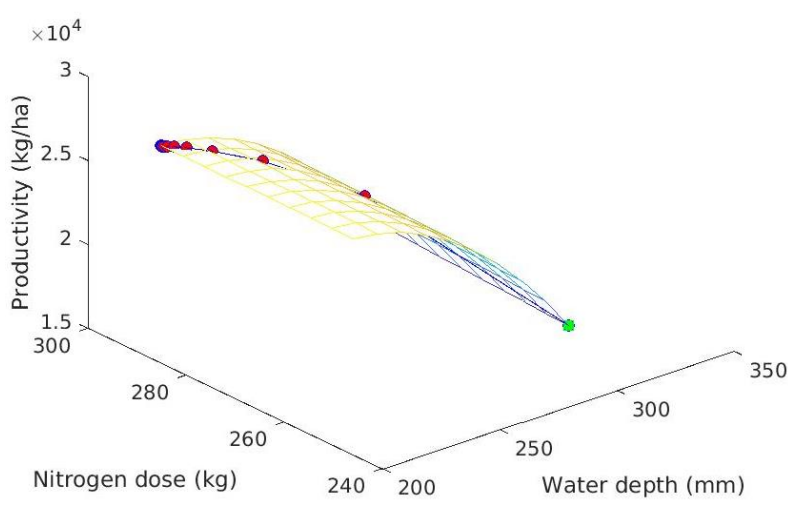

Melon

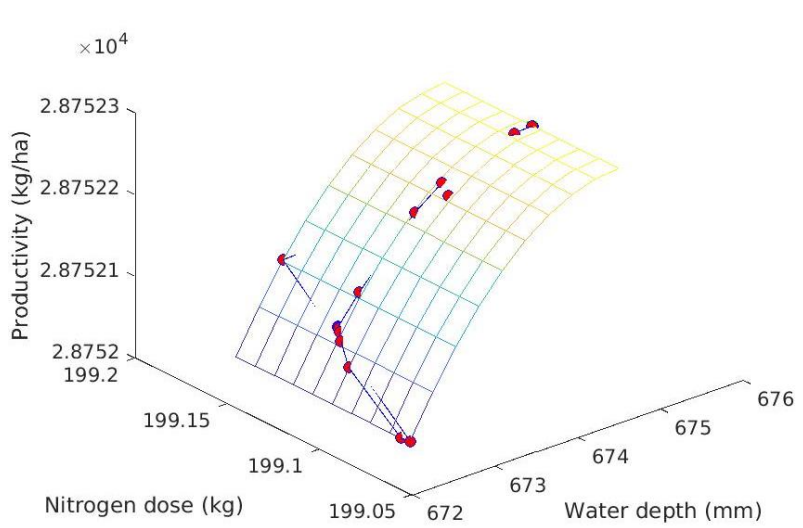

Oats

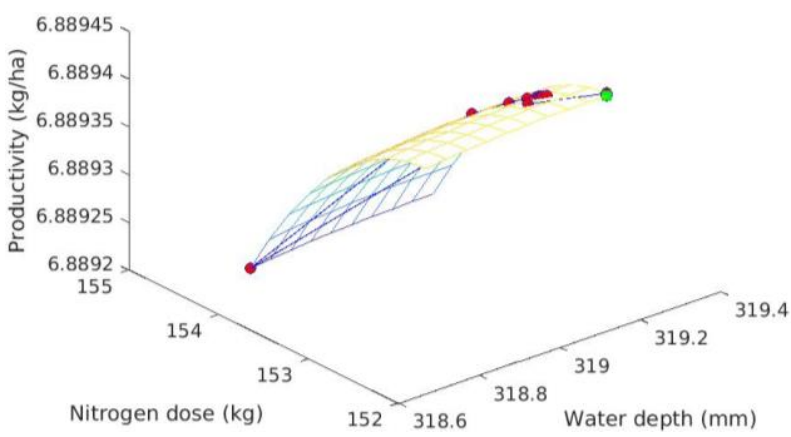

Orange

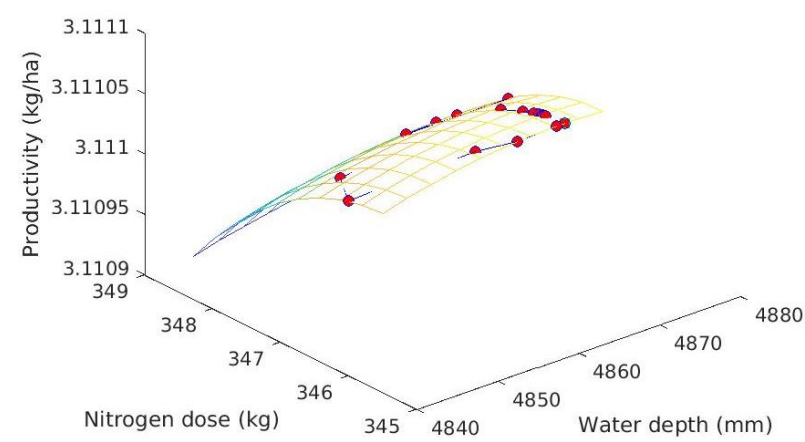

Figure 1. Optimum crop yield: lettuce, melon, orange pear and oats. 
Table 3 presents the results obtained by the Procedure, as well as the literature regarding the optimum net income for melon, american lettuce and oat crops.

Table 3. Water depth $w$, nitrogen dose $n$ and optimal net revenue $R L(w, n)$.

\begin{tabular}{lcccl}
\hline Cultures & Methodology & $\boldsymbol{w}(\boldsymbol{m m})$ & $\boldsymbol{n}(\boldsymbol{k g})$ & $\boldsymbol{R L}(\boldsymbol{w}, \boldsymbol{n})(\mathrm{net}$ revenue $)$ \\
\hline Melon & Procedure & 675.01 & 199.12 & $\mathrm{R} \$ 15.764 .74$ \\
& Rocha Junior et al. $(2016)$ & 597.1 & 198.3 & $\mathrm{R} \$ 10.440 .00$ \\
American Lettuce & Procedure & 199.93 & 263.55 & $\mathrm{R} \$ 20.895$ \\
& Marques Silva et al. (2008) & 203.98 & 240 & $\mathrm{R} \$ 20.931$ \\
Oats & Procedure & 319.20 & 152.35 & $\mathrm{R} \$ 893.4$ \\
& Frizzone et al. $(1995)$ & 310 & 120 & $\mathrm{R} \$ 897$ \\
\hline
\end{tabular}

Note that in the case of melon, there is a difference between net revenues in the Procedure and Rocha Junior et al. (2016) methodology of R\$ 5.324.74, although the Procedure must use $78 \mathrm{~mm}$ more water than that in Rocha Junior et al. (2016) and with almost the same amount of nitrogen. Regarding the american lettuce and oat crops the net revenue values do not present significant difference; we can only notice a small difference regarding the amount of nitrogen used. Analogous to Figure 1, in Figure 2, we can see each iteration of the implemented procedure as well as the central trajectory associated with the net income for melon, american lettuce and oat crops. As in Bertonha et al. (1999), we are only considering maximizing production and not maximizing net revenue. Therefore, we do not have a graphic representation for this culture in Figure 2.
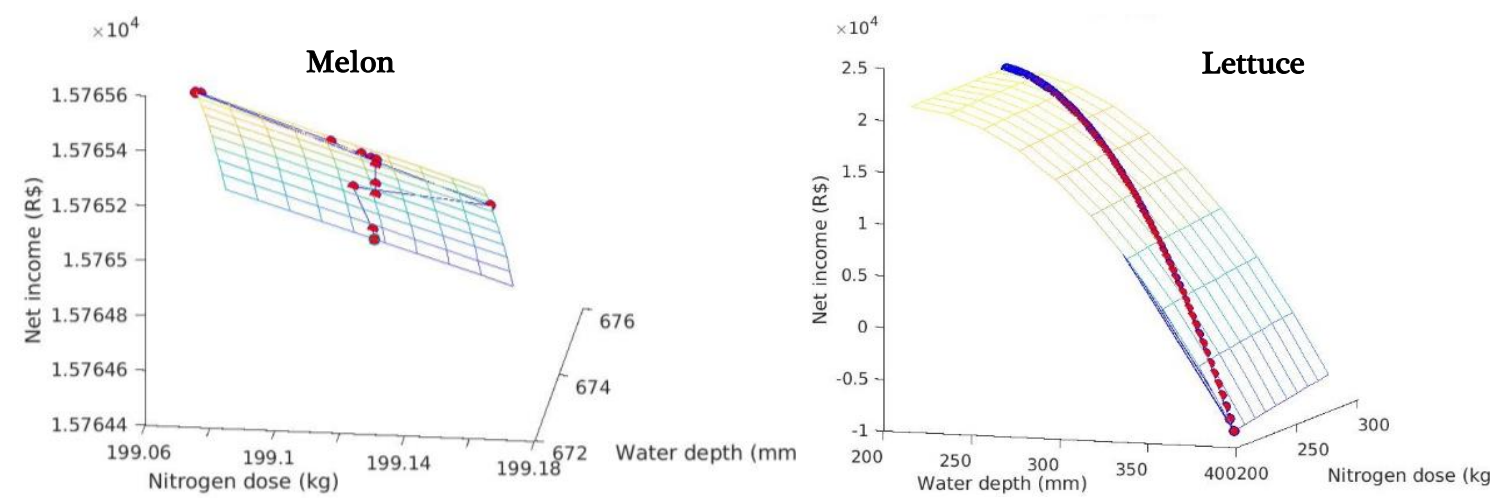

Oats

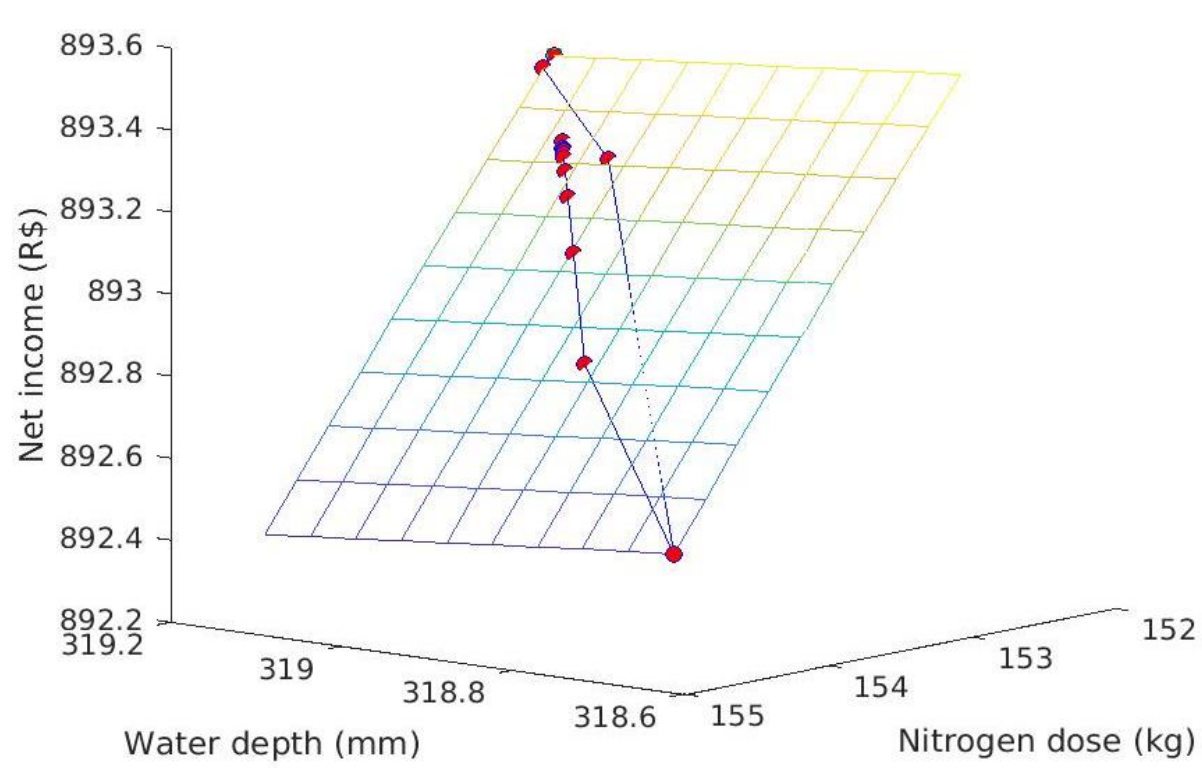

Figure 2. Optimum crop net revenue: melon, lettuce and oats. 
Table 3 again shows satisfactory results in relation to net revenue if we consider that in the last five years, Empresa Brasileira de Pesquisa Agropecuária (EMBRAPA) has registered an average net revenue of $16.750 R \$ . h a^{-1}$ for melon, $18.036 R \$ . h a^{-1}$ for american lettuce and $748 R \$ . h a^{-1}$ for oats respectively.

\section{Conclusions}

A computational methodology or Procedure (nonlinear programming) was presented to determine the maximum yield and/or maximum net income of a set of resource-limited crops using the duality theory. The Procedure was implemented in MATLAB 7.1. It is important to highlight the brilliant and simple performance of the dual problem in the construction of the Procedure. On the other hand, with the results obtained in this work, two questions are answered: the first is the numerical compatibility of the Procedure with the empirical methodologies used here, and secondly, that the use of logarithmic barrier type interior points in the Procedure presented here, iteratively allows you to visualize the convergence towards the optimal productivity solution or optimal net revenue solution. Finally, based on the results obtained, we may conclude that the Procedure presented constitutes a reliable alternative, considering the results similar to those published in the literature.

\section{Acknowledgments}

The authors are grateful to the anonymous reviewer for critically reviewing the manuscript.

\section{References}

Bazaraa M.S., Sherati H.D. \& Shetty C.M. (1993) No linear programming. Theory and Algorithms. $2^{\circ}$ edition. New York: Wiley. 638 p.

Bertonha A., Frizzone J.A. \& Martins E.N. (1999) Irrigação e adubação nitrogenada na produção de laranja pera. Acta Scientiarum, Agronomy, 12(3): 537-542.

https://doi.org/10.4025/actasciagron.v21i0.4281

Bertsekas D.P. (2004) Nonlinear Programming. Belmont: Athena Scientific. 780 p.

Figueiredo M., Frizzone J.A., Pitelli M.M. \& Rezende R. (2008) Lâmina ótima de irrigação do feijoeiro, com restrição de água, em função do nível de aversão ao risco do produtor. Acta Scientiarum, Agronomy, 30(1): 81-87. https://doi.org/10.4025/actasciagron.v30i1.1135

Frizzone J.A. (1986) Funções de resposta do feijoeiro (Phaseolus vulgaris L.) ao uso de nitrogênio e lâmina de irrigação. Tese (Programa de Pós-Graduação em Solos e Nutrição de Plantas). Universidade de São Paulo, Escola Superior de Agricultura Luiz de Queiroz, Piracicaba, São Paulo.

Frizzone J.A., Teodoro R.E.F., Pereira A.S. \& Botrel T.A. (1995) Lâminas de água e doses de nitrogênio na produção de aveia (Avena sativa 1.) para forragem. Scientia Agricola, 52(3): 578-586. http://dx.doi.org/10.1590/S0103-90161995000300027

Frizzone J.A., Andrade A.S., Souza J.L.M. \& Zocoler J.L. (2005) Planejamento de irrigação: análise de decisão de investimentos. Brasília: EMBRAPA. 627 p.

Hexem R.W. \& Heady E.O. (1978) Water production functions for irrigated agriculture. Ames: Iowa State University Press. 215 p.

Marques Silva P.A., Pereira Magela G., Reis R., Lima L.A. \& Taveira J.H. (2008) Função de resposta da alface americana aos níveis de água e adubação nitrogenada. Ciência $e$ Agrotecnologia, 32(4): 1266-1271. http://dx.doi.org/10.1590/S1413-70542008000400035

Rocha Junior A.F., Mousinho F.E.P, Soares A.C., Gomes E.R, Da Costa V. \& Salviano A.C. (2016) Resposta produtiva do meloeiro sob diferentes lâminas de água e doses de nitrogênio. Científica, 44(2): 217-225. http://dx.doi.org/10.15361/1984-5529.2016v44n2p217-225

Soares J.M., Brito L.T.L., Costa N.D., Maciel J.L. \& Faria C.M.B. (1999) Efeito de fertilizantes nitrogenados na produtividade de melão. Pesquisa Agropecuária Brasileira, 34: 1139-1143. 